\title{
O Cultivo de Organismos Geneticamente Modificados e a Contaminação da Água
}

\section{The cultivation of genetically modified organisms and the contamination of water}

\author{
Taís de Souza Santos ${ }^{1}$ \\ Francisco Roberto Silva de Abreu ${ }^{2}$
}

Artigo

Original

\section{Palavras-chave: \\ Danos ambientais}

Transgênicos

Agrotóxicos

Herbicidas

\section{Resumo}

Este artigo tem como objetivo discutir as consequências negativas associadas ao uso intensivo de agrotóxicos, herbicidas e fertilizantes nos cultivos de organismos geneticamente modificados . Tais consequências estão relacionadas, principalmente, aos danos ambientais e à saúde humana (de trabalhadores, famílias rurais e consumidores,) cujos custos acabam sendo socializados. O presente estudo analisa, a partir de dados obtidos por meio de Pesquisa e Revisão Bibliográfica, a contaminação da água como consequência do uso indiscriminado desses produtos. Conclui-se que o artigo pode contribuir para a formulação de políticas no sentido de auxiliar o desenho dos instrumentos de regulação e fornecer subsídios para a tomada de decisão mais rápida e eficiente em relação ao cultivo de organismos geneticamente modificados.

\begin{abstract}
Summary
This article aims to discuss the negative consequences associated with intensive use of pesticides, herbicides and fertilizers in the cultivation of genetically modified organisms. Such consequences are mainly related to environmental and human health (workers, families and rural consumers), the costs end up being socialized. This study examines, from data obtained through the Research and Literature Review, contamination of water as a consequence of the indiscriminate use of these products. It is concluded that the results can contribute to the formulation of policies to assist the design of regulatory instruments to provide information for decision-making faster and more efficient in the cultivation of genetically modified organisms.
\end{abstract}

Key words:

Environmental damage

GMO

Pesticides

Herbicides

\section{Introdução}

A agricultura é a atividade econômica mais antiga e importante do planeta, ocupando, atualmente, cerca de $38 \%$ da área global (World Resource Institute, 1994), gerando 1,3 bilhão de empregos e produzindo cerca de US\$ 1,3 trilhão ano-1 em matérias-primas e mercadorias (El Feky, , 2000).

Desde a sua invenção, há aproximadamente 10 mil anos, no período Neolítico, a agricultura é fundamentada na interferência do homem no ecossistema, inicialmente visando à maior extração e coleta de materiais essenciais à sobrevivência e, atualmente, direcionada à produção de alimentos e materiais de valor econômico. Como exemplo dessa interferência, podemos citar a procura por terras mais férteis, construção de diques de irrigação natural ou promoção da rotatividade do solo.

Com a constatação de que certos materiais orgânicos promovem a fertilização 
da terra, como os adubos de origem animal e vegetal, um considerável avanço se deu para a agricultura que, desde então, tem buscado constantemente novas tecnologias para melhorar a produção.

Umoutropontorelevante desse avanço foi a introdução de substâncias que controlassem as perdas decorrentes do ataque de pragas e ervas daninhas à lavoura. A utilização de agrotóxicos, substâncias com alto teor de toxicidade, destinadas a destruir específicos tipos de pragas, sem, entretanto, causar danos à plantação, tornou viável à agricultura de grande porte, voltada ao consumo interno e à exportação. Com isso, a plantação deixou de ser somente fonte de subsistência para os municípios adjacentes à propriedade agrícola, tornando-se um grande negócio, que nos dias de hoje movimenta uma considerável parcela do PIB de países como o Brasil.

A busca incessante por uma vida melhor e maior produtividade também tem levado o homem a enveredar pelo campo do conhecimento científico de uma forma ilimitada. A genética, após a descoberta de Mendel, passou por transformações abruptas no decorrer das décadas. A engenharia genética vem ganhando um destaque dentro do campo da ciência, na economia e política. Isso tem acontecido em decorrência do enorme potencial de transformação nos mais diversos campos da humanidade.

Como consequência dessa busca incansável por novos avanços na ciência e tecnologia, o homem chegou aos transgênicos, ou Organismos Geneticamente Modificados (OGMs). São considerados OGMs os seres vivos com material genético alterado pelo homem, através da transferência de um gene de uma espécie para outra. Eles surgiram há bem pouco tempo, na década de 70, e rapidamente alcançaram o mundo, principalmente os alimentos. Apesar disso, ainda é grande a polêmica em torno do assunto. Da medicina, a biotecnologia passou para a agricultura, onde proliferou. A discussão sobre esses alimentos está longe de alcançar consenso. Enquanto para alguns a nova tecnologia é uma certeza de desenvolvimento, para outros muito ainda deve ser esclarecido sobre os reais impactos no meio ambiente, na saúde, política, economia e bioética de cada país (ALVES, 2004).
Do outro lado da questão, se encontram ambientalistas e pessoas que se preocupam com a qualidade dos alimentos que consumimos diariamente. As pesquisas sobre transgênicos são bastante recentes e não se têm dados que comprovam a qualidade ou a segurança desses produtos a longo prazo. Além disso, plantas super-resistentes apenas agravariam o quadro do uso indiscriminado de agrotóxicos, que já se encontra bastante grave. Seria iminente o uso de agrotóxicos mais fortes e em maior quantidade e, dessa forma, os prejuízos ao meio ambiente e a saúde das pessoas seria inestimáveis (ODILON, et al.).

A utilização indiscriminada desses produtos aliada a fatores como a falta de conhecimento técnico de certos produtores, a ausência de fiscalização, o poderio de grandes empresas agrícolas, a falta de consciência ambiental e o problema da poluição das águas vêm trazendo sérios prejuízos ao ambiente e à saúde das pessoas, seja de forma direta ou indireta.

Os recursos hídricos agem como integradores dos processos biogeoquímicos de qualquer região. Sendo assim, quando pesticidas são introduzidos, os recursos hídricos, sejam superficiais ou subterrâneos, aparecem como o destino final principal dos pesticidas. Solo e água atuam interativamente e qualquer ação que cause efeito adverso em um destes elementos afetará o outro. É importante ressaltar que, em alguns casos, menos de $0,1 \%$ da quantidade de pesticidas aplicados alcançam a peste alvo, enquanto o restante $(99,9 \%)$ tem potencial para se mover para outros compartimentos ambientais, como as águas superficiais e subterrâneas (RIBEIRO, 2007)

\section{Organismos Geneticamente Modificados}

Os OGMs surgiram em 1973 quando os cientistas Cohen e Boyer, que coordenavam um grupo de pesquisas em Stanford e na University of Califórnia, davam o passo inicial para o mundo da transgenia. Eles conseguiram transferir um gene de rã para uma bactéria, o primeiro experimento ocorrido com sucesso usando a técnica do DNA recombinante. Essa técnica, posteriormente, passou a ser chamada de engenharia genética. De acordo com Furtado 
(2003) "Essa conquista tem sido comparada à domesticação do fogo e à descoberta da fissão nuclear, entre outros eventos de grande impacto sobre o destino humano".

Convencionalmente utilizam-se os termos OGMs e transgênicos como sinônimos, Porém, existe uma diferença técnica entre ambos. Os OGMs, são organismos que foram modificados com a introdução de um ou mais genes provenientes de um ser vivo da mesma espécie do organismo de alvo. Um exemplo típico de OGM é o tomate Flavr savr, que foi modificado geneticamente para apresentar um processo de maturação mais lento, de modo a permitir que os frutos possam ser colhidos maduros ainda na planta. Isso faz com que a qualidade nutricional e de acondicionamento sejam melhores. Essa técnica de modificação consiste em isolar uma determinada sequência de genes do próprio fruto e depois inserí-la em sentido inverso, no próprio fruto. Assim, temse um OGM e não um transgênico. O termo transgênico, foi usado pela primeira vez em

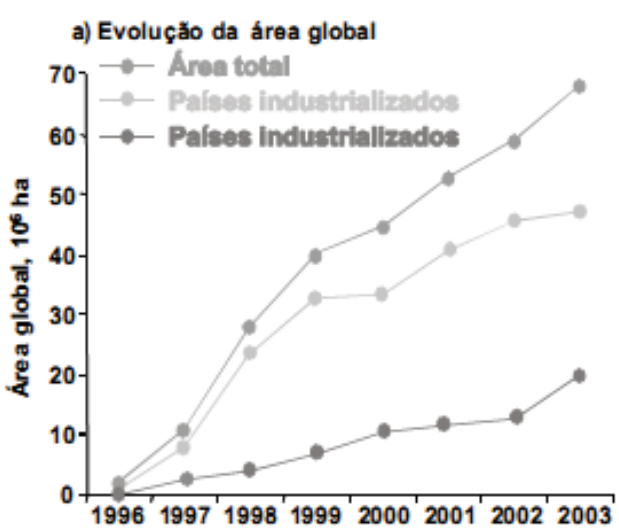

\section{Por que produzir OGMs?}

As características procuradas são, geralmente, de melhoria na qualidade (cor, textura, tamanho), tempo de duração e elementos nutricionais de vegetais. Pode-se também buscar elementos ligados à produção do alimento tais como: resistência a pragas (vírus, insetos, etc.) e resistência a herbicidas. Essas características tornam mais baratas e aumentam a produção das plantações.

Há também a possibilidade de produzir organismos que não causem alergias ou que não tenham substâncias antinutricionais (que atrapalham o uso de nutrientes pelo organismo), ou ainda, que produzam remédios e vacinas ( ROSA, s.d.).
1983, na Universidade da Pensilvânia, quando dois cientistas inseriram genes humanos de hormônios de crescimento em embriões de ratos, produzindo os chamados "super ratos". A palavra transgênico é utilizada para designar um ser vivo que foi modificado geneticamente, recebendo um gene ou uma sequência gênica de um ser vivo de espécie diferente. Para a execução de tal processo, utiliza-se a tecnologia DNA recombinante. Como exemplos de transgênicos, temos uma imensa gama de alimentos consumidos diariamente em diversos países sem que se tenha ciência dos processos de produção (ALVES, 2004). A figura abaixo ilustra o crescimento do uso de sementes geneticamente modificadas no mundo.

Evolução da área global plantada com culturas transgênicas entre 1996 e 2003 em países industrializados e em desenvolvimento (a) e distribuição das principais culturas em 2003 (b). Fonte: James (2003).

b) Distribui çăo das principais culturas em 2003

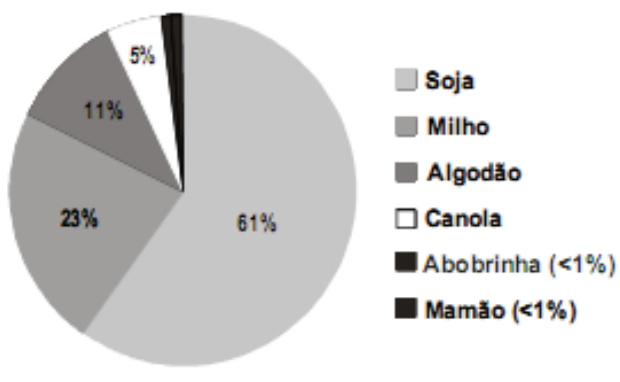

\section{OGMs e sua resistência a fertilizantes, herbicidas e agrotóxicos}

Contudo, por trás desse desenvolvimento científico se encontra uma grande discussão ideológica decorrente de interesses financeiros por parte de uma poderosa indústria de força mundial: a indústria dos agrotóxicos. Essas empresas financiam a pesquisa de novas espécies transgênicas buscando o desenvolvimento de plantas super-resistentes à ação dos agrotóxicos, sendo que dessa forma os prejuízos pela ação de pragas seriam minimizados através da utilização de venenos mais fortes e devastadores. Além disso, especula-se o desenvolvimento de espécies 
cujos únicos agrotóxicos compatíveis seriam aqueles produzidos por determinada empresa que, dessa forma, obteria monopólio mundial.

Segundo JAIME (2007), as preocupações ambientais não devem ser restritas apenas à questão do fluxo de genes, mas também aos impactos negativos que podem estar causando os avanços tecnológicos que estão intimamente ligados a estes cultivos: grandes monoculturas em larga escala, reduzindo a biodiversidade (tanto do cultivo como da flora e fauna), e os efeitos da aplicação contínua de agrotóxicos, principalmente apenas um tipo de herbicida (no caso do OGM resistentes a eles, que, são atualmente a maioria das áreas plantadas). Isso foi provado, entre outros, em estudos de Firbank e Forcella (2000), Watkinson et al. (2000), Brooks et al. (2003), Hågvar e Aasen (2004), Benbrook (2005) e Bohan et al. (2005), bem como a pesquisa citada nos trabalhos da Mellon e Rissler (2003), Milius (2003), Bravo (2005) e Garcia e Altieri (2005). Enquanto isso, Nottingham (2002), Grain (2004) e Altieri (2005) veem que a contaminação genética, ou seja, o risco da passagem do transgene para outros indivíduos na natureza e suas consequências, deve ser vista como uma consequência inevitável da agricultura com a OGM, o que aumenta o controle das grandes empresas sobre ele.

A engenharia genética tem produzido, principalmente, dois tipos de plantas geneticamente modificadas: as que possuem tolerância a herbicidas e as plantas resistentes a insetos. A soja resistente ao glufosinato de amônio (nome comercial Liberty), semente obtida pela engenharia genética, é um bom exemplo de planta tolerante a herbicidas. As sojas normais não toleram os herbicidas não seletivos, comumente utilizados para controle das plantas daninhas; por isso, as pulverizações são feitas em soja pré-emergente, ou em pós-emergência com herbicidas seletivos. A engenharia genética produz soja resistente aos herbicidas, introduzindo no genoma da soja um gene capaz de inibir a enzima glutamina sintetase e a formação de amônia, o elemento responsável pela morte da planta. $\mathrm{O}$ gene de tolerância foi obtido e foram desenvolvidos

\section{Modificação doDNAdaPlanta para torná-la resistente ao herbicida}

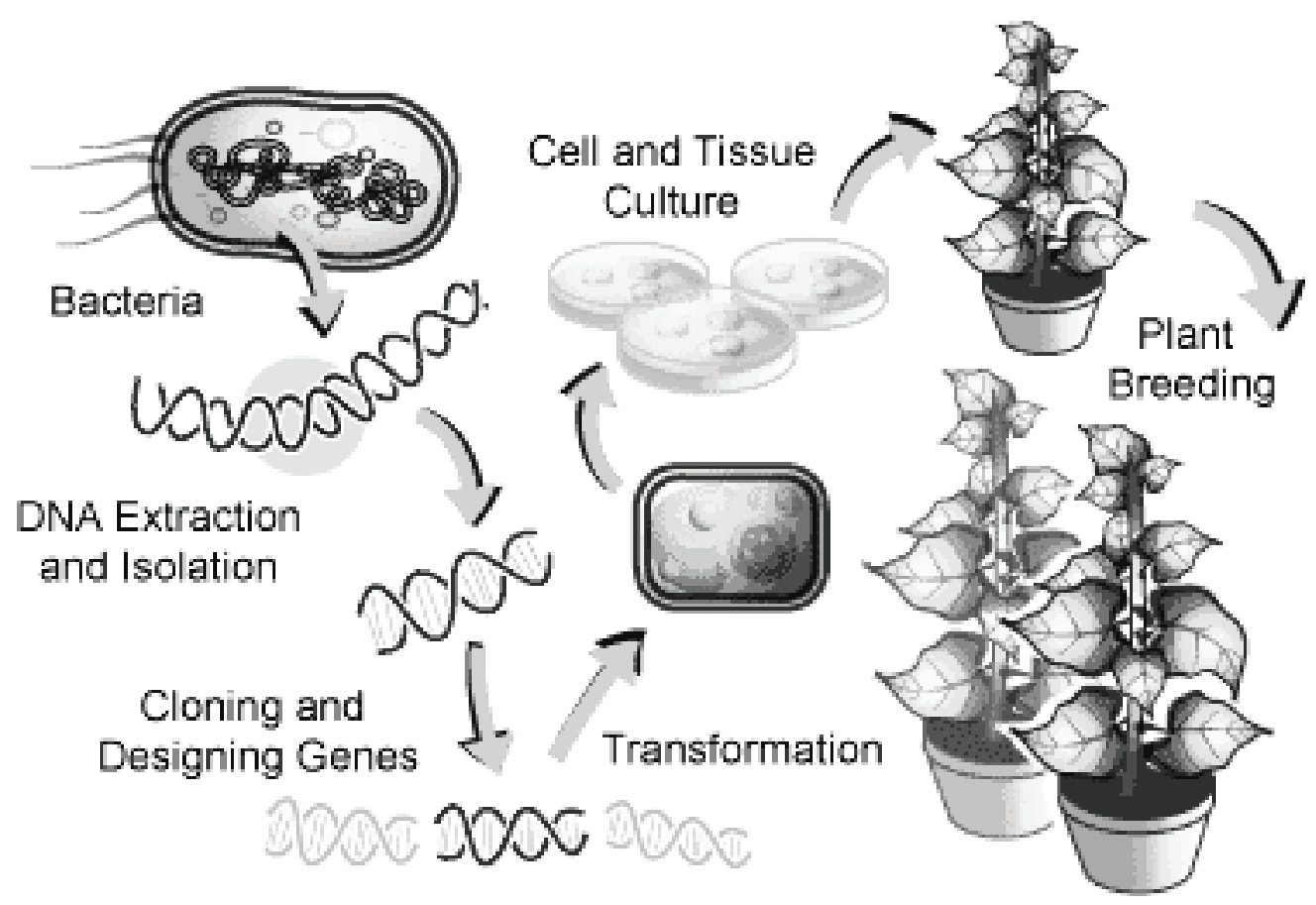


milho, arroz e cana-de-açúcar resistentes ao glufosinato de amônio (ODILON, 2009).

\section{Contaminação da água por fertilizantes e agrotóxicos}

A água doce presente no planeta Terra representa apenas $2,70 \%$, sendo que dessa parte $2,07 \%$ estão congeladas. Apenas $0,63 \%$ de toda a água do planeta é de água que podemos consumir, e ainda, parte dessa água não está totalmente disponível por inviabilidade técnica, econômica, financeira e de sustentabilidade ambiental. Só esses dados e porcentagens já nos dão a dimensão da importância de um consumo mais consciente da água doce do planeta e do cuidado que devemos ter para mantê-la potável e disponível para consumo, tanto humano quanto dos demais seres vivos que dela necessitam para sobreviver.

A preocupação com a contaminação de sistemas aquáticos superficiais e subterrâneos por pesticidas tem crescido no meio científico.

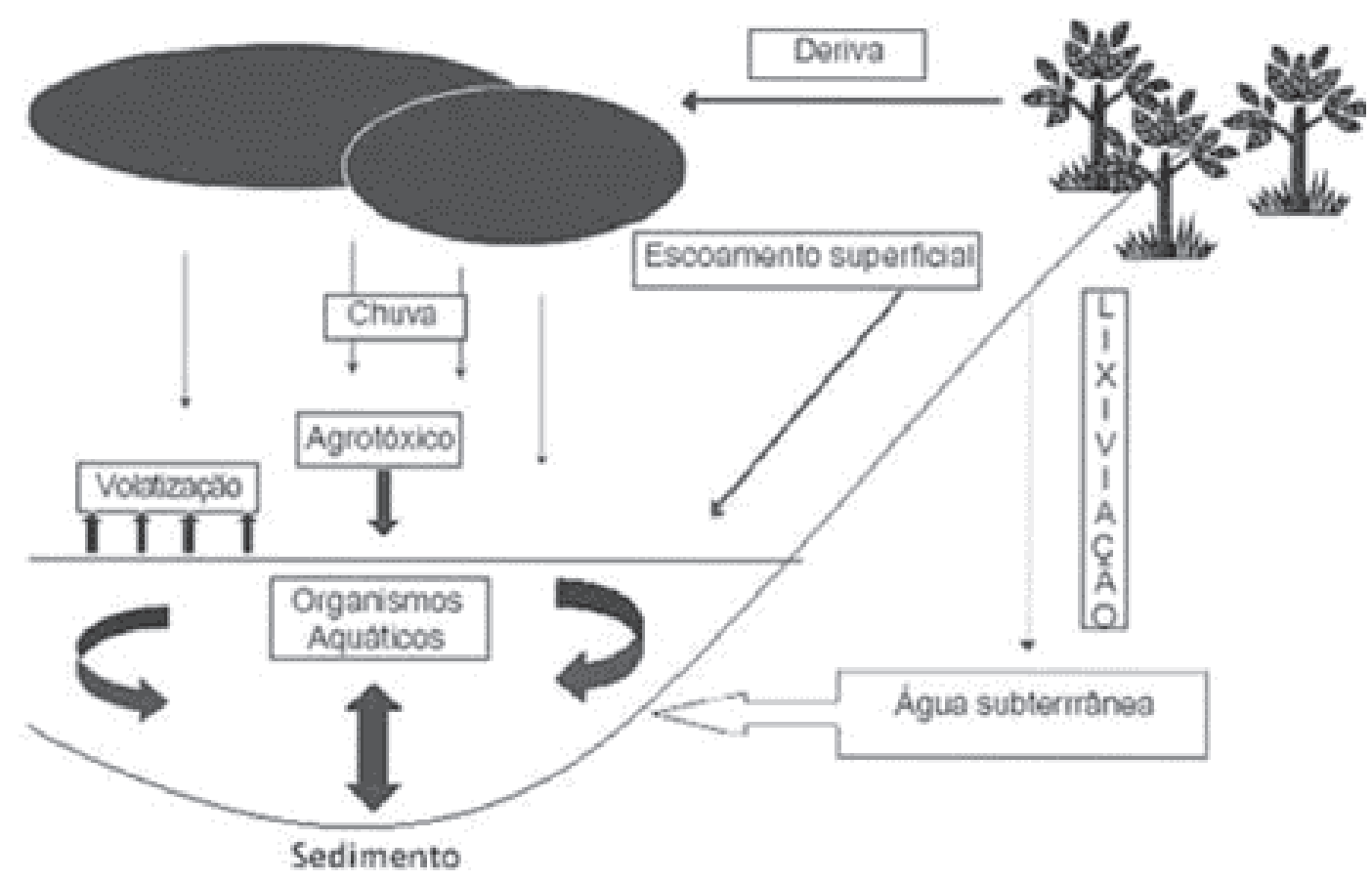

Contaminação da água pelo excessivo uso de herbicidas, agrotóxicos e etc.

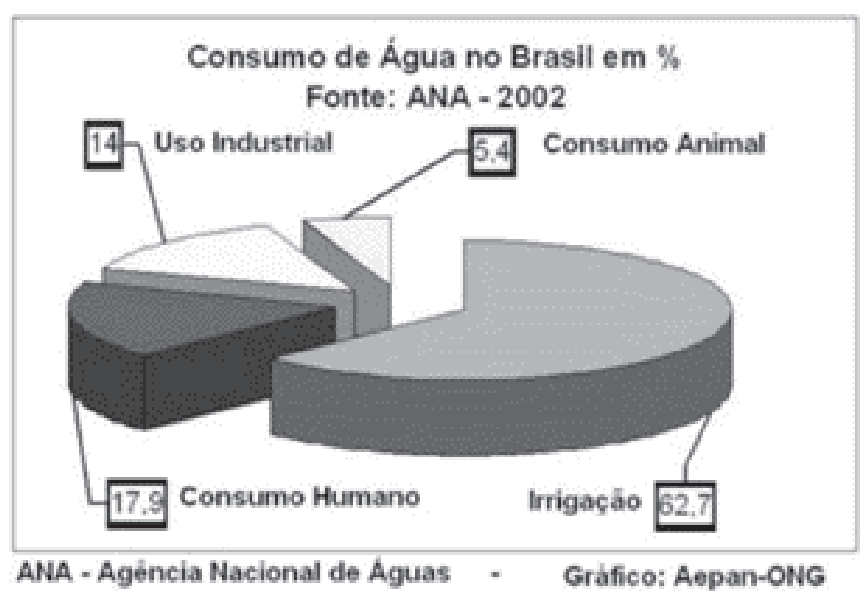

Estudos desenvolvidos em várias regiões do mundo têm mostrado que a porcentagem dos produtos utilizados na agricultura que atingem os ambientes aquáticos é geralmente baixa. Entretanto, pesticidas persistentes e com grande mobilidade no ambiente têm sido detectados em águas superficiais e subterrâneas. 
A concentração da maioria dos pesticidas em água é baixa, em parte, devido ao fato de serem geralmente pouco solúveis em água e, em parte, devido ao efeito de diluição. Isso, no entanto, não exclui a possibilidade de que concentrações muito altas venham a ocorrer após pesadas chuvas, especialmente quando as áreas ao redor de um pequeno córrego tenham sido recentemente tratadas com altas doses de pesticidas. Mesmo em concentrações baixas, os pesticidas representam riscos para algumas espécies de organismos aquáticos que podem concentrar esses produtos até 1000 vezes. Não existe nível seguro previsível para pesticidas em água quando pode ocorrer biomagnificação. (DORES, 2001)

$\mathrm{O}$ problema da poluição devido à utilização de fertilizantes se dá devido ao escoamento de parte desse material aos rios, movido pela chuva ou por sistemas de irrigação. Os fertilizantes naturais têm origem orgânica e não trazem prejuízos ao meio ambiente, contudo, nos dias de hoje é habitual o uso de fertilizantes químicos, mais eficientes e específicos para cada tipo de cultura. Esses produtos contêm em sua formulação substâncias como fósforo e nitrogênio que, em quantidades exageradas, não conseguem ser assimiladas pelos rios e podem causar problemas aos consumidores das águas. O fenômeno da floração da água ocorre quando fertilizantes agrícolas despejados nos rios nutrem excessivamente as plantas aquáticas, alterando a coloração da água para tons esverdeados.

Entretanto, os problemas mais graves se dão devido ao uso dos agrotóxicos. Os prejuízos causados ao meio ambiente pela utilização descontrolada e muitas vezes de forma errônea desses produtos são inestimáveis sendo que seus efeitos atingem uma faixa muito ampla do ambiente. Podem-se identificar vários níveis de contaminação decorrente do mau uso de agrotóxicos:

- com a chuva ou sistemas de irrigação, o tóxico escoa diretamente para o curso d'água, onde os prejudicados imediatos são os peixes e animais aquáticos. Essa mortalidade causa sérios desequilíbrios à cadeia alimentar, além de afetar de forma indireta a população ribeirinha que tem a pesca como fonte de subsistência;

- $\quad$ os agrotóxicos têm em sua composição substâncias químicas solúveis, que se dissolvem na água do rio, que é consumida por animais selvagens e domesticados, além da própria população ribeirinha. Além disso, certas substâncias químicas passam inalteradas pelo sistema de tratamento de água, atingindo dessa forma uma incalculável parcela da população abastecida pelo sistema público;

- parte do tóxico dissolvido infiltra juntamente com a água, entrando no fluxo subterrâneo e contaminando indiretamente os rios e nascentes, podendo também afetar aquíferos, trazendo prejuízos às maiores reservas naturais de água do planeta;

- devido ao precário sistema de segurança no trabalho e a ausência de fiscalização, muitos trabalhadores são afetados diretamente pelos tóxicos no momento do preparo e aplicação do produto, e até mesmo pelo contato indireto prolongado, que a longo prazo pode afetar a saúde do indivíduo;

- certas substâncias químicas podem ficar aderidas à superfície do produto agrícola, comprometendoconsideravelmenteaqualidade dos alimentos. Por isso se faz necessária uma cuidadosa lavagem de produtos naturais por parte da população para minimizar o risco de contaminação;

- um tipo de aplicação de agrotóxicos muito utilizada nos dias de hoje é a pulverização aérea, na qual um aspersor é acoplado a uma aeronave, que lança o veneno sobre toda a área de aplicação de forma rápida e contínua. Como as partículas lançadas são bastante pequenas, parte da substância é facilmente carregada pelo vento, podendo atingir rios, matas e zonas habitadas. Existe uma regulamentação que estabelece limites de distâncias entre a área de aplicação e áreas habitadas, limites estes que nem sempre são respeitados devido à falta de fiscalização.

\section{6 - Danos causados pelos pesticidas e agrotóxicos}

Os pesticidas quase sempre são substâncias tóxicas e, quando consumidos por seres humanos, através de produtos contaminados, podem causar problemas 
de saúde como dificuldades respiratórias, problemas de memória, problemas na pele, vários tipos de câncer, além de outras intoxicações. ( ODILON )

O glufosinato de amônio e o glifosato são utilizados em cultivos transgênicos tolerantes a herbicidas, que, atualmente, representam 75\% de todos os cultivos transgênicos espalhados no mundo. Ambos os produtos são venenos metabólicos sistêmicos com uma ampla gama de efeitos nocivos previstos, que têm sido confirmados. O glufosinato de amônio está associado às toxicidades neurológica, respiratória, gastrointestinal e hematológica, bem como a defeitos congênitos em seres humanos e mamíferos; é tóxico para numerosos insetos benéficos, larvas de mexilhões e de ostras, crustáceo Daphnia, conhecido como pulga d'água, e certos peixes de água doce, em especial, para a truta arco-íris, além de inibir o desenvolvimento de bactérias e fungos benéficos do solo, especialmente os organismos que fixam nitrogênio.

O glifosato é a causa mais frequente de reclamações e casos de envenenamentos na Inglaterra. Foram registrados numerosos transtornos fisiológicos, após exposições a níveis normais de uso. A exposição ao glifosato praticamente duplicou o risco de abortos espontâneos, e os filhos nascidos de pessoas que utilizam o glifosato, com frequência apresentaram um elevado índice de transtornos de neurocomportamento. $\mathrm{O}$ glifosato provocou atraso no desenvolvimento do esqueleto fetal em ratos de laboratório, inibe a síntese de esteroides e é um agente genotóxico em mamíferos, peixes e sapos. A exposição de minhocas às doses habitualmente aplicadas no campo provocou mortalidade de, pelo menos, $50 \%$, e ainda, lesões intestinais importantes entre as sobreviventes. O Roundup provocou alterações no processo de divisão celular, as quais podem estar associadas com alguns tipos de câncer em seres humanos.

Os cultivos transgênicos modificados para serem tolerantes à formulação de glifosato da Monsanto, denominada Roundup Ready, são modificados com dois genes principais. Um gene favorece a diminuição de sensibilidade ao glifosato e o outro permite que a planta degrade o glifosato. A expressão de ambos os genes é dirigida aos cloroplastos, que é o local de ação do herbicida, em função da agregação de sequências codificadoras de um "peptídeo de transporte" derivado da planta. O primeiro gene codifica uma versão derivada de bactéria da enzima da planta, envolvida na via bioquímica do shiquimato. Diferentemente da enzima da planta, que é sensível ao glifosato e provoca o fim do crescimento da planta ou sua morte, a enzima bacteriana é insensível ao glifosato. O segundo gene- também bacteriano, codifica para uma enzima que degrada o glifosato, a sequência codificadora foi alterada para aumentar a atividade de degradação do glifosato.

A via shiquimato-corismato não é encontrada em seres humanos e mamíferos e, como tal, representa "um novo alvo", embora esteja presente em uma variedade de micro-organismos. Contudo, o glifosato atua impedindo a união do metabólito fosoenol piruvato (PEP) ao sítio da enzima Schonbrunn et. al (2001). O PEP é um metabólito central, presente em todos os organismos, incluindo os seres humanos. O glifosato, então, tem o potencial de alterar muitos sistemas enzimáticos importantes que utilizam PEP, inclusive o metabolismo energético e a síntese de lipídeos da membrana, necessários às células nervosas

A aplicação de glifosato no controle convencional de ervas daninhas provoca a destruição e extinção local de espécies vegetais ameaçadas de extinção. Nos ecossistemas florestais, reduz, significativamente, briófitas e líquens. O tratamento de plântulas de feijão com glifosato resultou em aumento de patógenos do solo que causam tombamento, em curto prazo.

A aplicação de glifosato para controlar espéciesinvasorasemzonasribeirinhas, sujeitas a enchentes, ocasionou efeitos secundários imprevistos. O glifosato persiste no solo e na água subterrânea, sendo encontrado em poços de água localizados nas proximidades de áreas que sofreram aplicação do herbicida. Existem muitos estudos científicos já publicados mostrando que o aumento "massivo" do uso de glifosato em conjunto com os cultivos transgênicos representa uma ameaça importante para a saúde humana e animal, bem como para o meio ambiente. (Grupo de Ciência Independente, 2004) 


\section{7 - OGMs e o uso abusivo de herbicidas}

A comercialização de culturas resistentes aos herbicidas é uma questão polêmica, principalmente, no que diz respeito ao impacto ambiental que pode acarretar. HARRISON (1992) apresenta uma abordagem positiva, ressaltando que o desenvolvimento de cultivares resistentes está sendo acompanhado por redução na busca de novos herbicidas. WIESE (1992), em um sentido oposto, pondera que uma tecnologia pode ter aspectos positivos ou negativos dependendo de como é utilizada. Aponta alguns possíveis riscos, tais como: seleção de biótipos resistentes ou de espécies de plantas daninhas tolerantes, devido ao uso contínuo de herbicidas com o mesmo mecanismo de ação, e necessidade de pesquisas mais profundas em relação à segurança de alimentos e à qualidade da água, quando utilizado OGM no ambiente MONQUERO (2005).

Segundo QUILES (2009), o solo e a água podem ser contaminados pelo uso excessivo de herbicidas, pois o uso frequente dessa substância pode selecionar ervas daninhas resistentes a ela, sendo necessário, então, o uso de quantidades cada vez maiores. Ou pelas substâncias produzidas pelos vegetais modificados, como, por exemplo, inseticidas.

Mais de $75 \%$ dos cultivos transgênicos, plantados atualmente em todo o mundo, são manipulados geneticamente para serem tolerantes a herbicidas de amplo espectro, fabricados pelas mesmas empresas que obtêm a maioria do seu lucro da venda de herbicidas. Esses herbicidas, de amplo espectro, não apenas matam plantas indiscriminadamente, mas também são perigosos para praticamente todas as espécies de animais silvestres e para os seres humanos (Grupo de Ciência Independente, 2004).

Nos agrossistemas, empregando OGMs tolerantes a herbicidas, a ênfase tem sido para os efeitos indiretos dos herbicidas para os quais a cultura é tolerante e não propriamente àqueles causados pelos transgenes que, em sua maioria, são originados de bactérias de ocorrência comum no solo, como Streptomyces e Agrobacterium, ou mesmo de plantas. No caso dessas plantas transgênicas, o produto da expressão gênica são enzimas ligadas ao metabolismo da planta ou mecanismo de ação do herbicida e não à produção de toxinas (GIANESSI et al., 2002). Em lavouras com cultivares tolerantes, a glifosato, por exemplo, é aplicado em pós-emergência, atuando diretamente no sistema planta daninhacultura-organismos, onde atua seletivamente, eliminando as plantas daninhas sem causar danos diretos à cultura. Já nos cultivos convencionais, geralmente empregam-se herbicidas com ação pré-emergente, aplicados em solo descoberto e, posteriormente, herbicidas de pós-emergência.

Segundo Holt et al. (Apud ALTIERI, 1997 ) quando se aplica um só herbicida, de forma continuada sobre uma lavoura, elevam-se as chances de que se desenvolvam resistências ao produto, na população de plantas invasoras. Na medida em que grande parte das pesquisas com transgênicos propõese a desenvolver tolerância a herbicidas nas plantas, cria-se o temor de que a difusão dessa tecnologia implique na elevação do uso desses agroquímicos nas lavouras brasileiras, com consequente aumento da poluição do meio ambiente e prejuízo à microfauna, bactérias e outros seres vivos presentes no complexo solo-água. Todas estas possibilidades ensejariam ocorrências que redundariam, inquestionavelmente, em importantes alterações no equilíbrio dos ecossistemas (FREIXO, s.d.).

Em cultivos transgênicos, o forte efeito dos herbicidas sobre plantas daninhas pode interferir indiretamente na fauna do agrossistema, como pássaros (Champion et al., 2003), e na ecologia das invasoras. Na PGM, planta geneticamente modificada, as mudanças fisiológicas que garantem a tolerância aos herbicidas podem afetar a biota associada, em virtude das alterações na qualidade dos exsudatos. A aplicação do herbicida também tem efeitos diretos sobre a biota e processos bioquímicos do solo, e indiretos sobre a deposição de matéria 
orgânica na superfície do solo. (SIQUEIRA, 2004)

Segundo SIQUEIRA (2004), a redução no uso de defensivos em cultivos transgênicos favorece a biodiversidade, mas o uso prolongado do glifosato ou de cultivares Bt pode favorecer a evolução de

\section{Venda de fertilizantes químicos no Brasil}

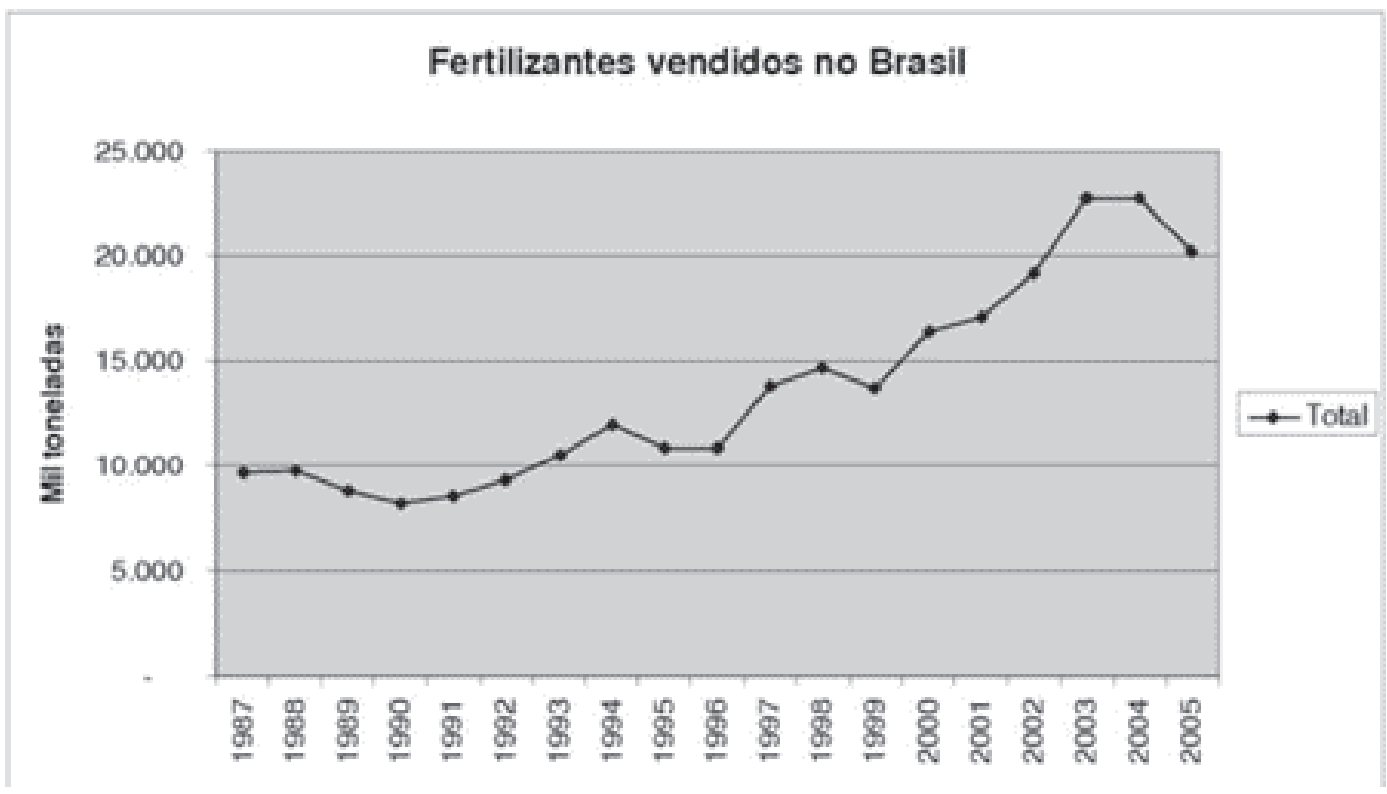

\section{Vendas de defensivos agrícolas, por categoria}

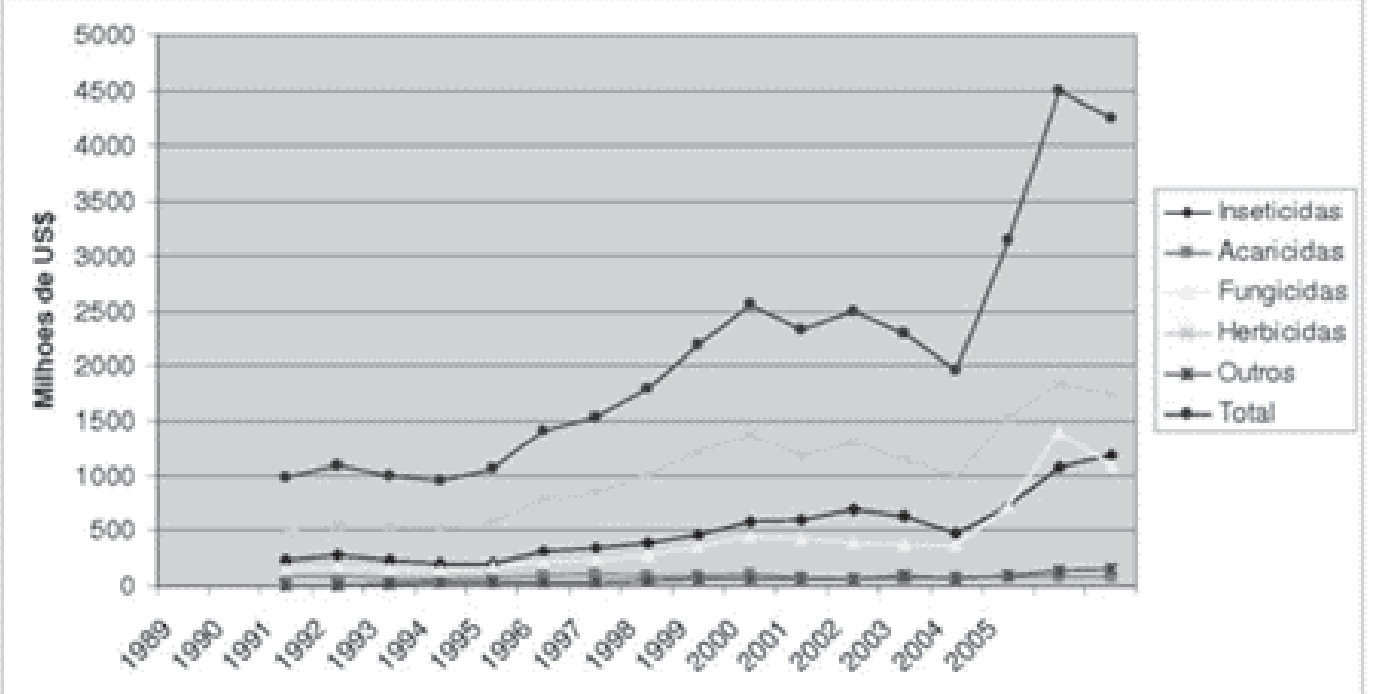

resistência e a poluição ambiental, riscos inerentes a qualquer tipo de cultivo.

$\mathrm{Na}$ Argentina, desde 1996, o ano em que a soja resistente ao glifosato (RR) foi amplamente cultivada pela primeira vez, a área destinada à produção de soja aumentou em uma proporção extraordinária de 2,4 vezes, passando de 6 milhões de hectares para 14,2 milhões em 2003/2004 (SAGPyA, 2004). Dada a expansão do número de hectares cultivados com soja RR, não é de se surpreender que o uso do herbicida glifosato tenha aumentado de maneira drástica. $\mathrm{O}$ uso total de glifosato na soja aumentou em 56 vezes de 1996/97 a 2003/04 e em $24 \%$ de $2002 / 03$ a $2003 / 04$ (CASAFE, 2004). Depender de um único herbicida, ano após ano, acelera a seleção de biótipos de plantas daninhas resistentes e espécies tolerantes. Na Argentina, PAPA et al. (2002) listaram as seguintes espécies de 
plantas daninhas tolerantes e que se tornaram problemas em áreas cultivadas por soja RR: Parietalia debilis, Petunia auxiliares, Verbena litoralis, Verbena bonariensis, Hybanthus parviflorus, Iresine difusa, Commelina erecta e Ipomoea spp.

\section{8 - Análise de risco}

A atividade agrícola, especialmente o uso de pesticidas, é considerada uma das atividades mais difíceis de serem avaliadas, uma vez que o comportamento dos diversos pesticidas utilizados é ainda pouco conhecido em subsuperfície e sua aplicação é ampla e efetuada em baixas concentrações. Embora a maior preocupação devido a essa atividade seja a contaminação por fertilizantes inorgânicos, nitrato principalmente, a literatura tem apresentado trabalhos que relatam a presença de diversas classes de pesticidas em água subterrânea. Sendo assim, mais atenção deve ser destinada a essas substâncias que são utilizadas em larga escala na agricultura (RIBEIRO 2007).

A avaliação de riscos consiste de um processo científico, passo a passo, que analisa os efeitos adversos causados pelo OGM (WOLFENBARGER \& PHIFER, 2000). No caso de riscos ambientais, tal avaliação é muito complexa e difícil de ser realizada, em virtude da natureza multi e interdisciplinar dos fatores ou componentes do risco (PETERSON et al., 2000).

Todos os aspectos relacionados ao hábitat e à ecologia geral da região e sistema de manejo da cultura, onde o OGM será liberado, precisam ser considerados. Portanto, os agrossistemas e suas imediações são complexos demais para que todos os riscos possam ser identificados e quantificados em análise à priori (MARVIER, 2001; DALE et al., 2002).

Para GOLDBURG (1992), as consequências ambientais, devido ao uso de culturas resistentes aos herbicidas, podem variar e dependem de fatores tais como: a espécie geneticamente modificada, quais herbicidas serão utilizados na cultura resistente e a segurança destas plantas modificadas como alimento humano e animal. Ressalta também, a possibilidade de aumento no uso de herbicida, recomendando, portanto, políticas que priorizem as pesquisas do setor público para o estudo do impacto global desta nova tecnologia (MONQUERO, 2005).

\section{9 - Conclusões}

Embora a sobrevivência da nossa espécie dependa da água, só recentemente a humanidade começou a refletir sobre a evolução e o destino da água no mundo. A água é o sangue do nosso planeta: ela é fundamental para a bioquímica de todos os organismos vivos. Os ecossistemas da Terra são sustentados e interligados pela água, que promove o crescimento da vegetação e oferece um habitat permanente a muitas espécies.

A realidade é que a produção de alimentos não conseguirá acompanhar o crescimento populacional, sendo necessário cada vez mais aumentar a produtividade e as áreas cultivadas. É preciso desenvolver novos métodos e tecnologias de produção que dinamizem a agricultura para que as pessoas não sofram ainda mais com a falta de alimentos.

É importante considerar que a agricultura atual também apresenta problemas como: alto custo de produção; dependência de recursos não renováveis; poluição de solo e água; impactos à biodiversidade; erosão genética (monoculturas); não garantia da segurança alimentar (resíduos de pesticidas) e saúde dos trabalhadores (insalubridade); e a maioria dos insumos é de domínio de multinacionais.

É necessário buscar um novo modelo, capaz de garantir produção estável e viável do ponto de vista econômico, social e ecológico. Esse novo modelo deve atender certos princípios básicos da sustentabilidade, como: elevada eficiência biológica e econômica; reduzido impacto ambiental; equidade social e alimentos com qualidade nutricional e seguros.

O cultivo de organismos geneticamente modificados poderá ser uma saída para o aumento de produção de alimentos, porém, seria mais racional esperar que mais testes e pesquisas fossem realizados para que houvesse uma maior consciência de todos os males e 
benefícios que os OGMs podem trazer ao ecossistema em geral antes de liberá-los para cultivo.

\section{Referências}

ALTIERI, M. Riesgos ambientales de los cultivos transgénicos: una evaluación agroecológica. Berkeley, USA: University of California, 1997.

ALTIERI, Miguel. Biotecnologia Agrícola: mitos, riscos ambientais e alternativas. Petrópolis: Editora Vozes, 2004.

ALVES, G. S. A Biotecnologia dos Transgênicos: precaução é a palavra de ordem, HOLOS, Ano 20, outubro/2004

ANDRADE FILHO, G.; BERGER, G. U.; FAVORETTO, L. R. G.; LAVRIK, P. B. Soja Roundup Ready®: estudo piloto de avaliação ambiental no Brasil. São Paulo, Monsanto, 2003. 38 p.

ARAÚJO, José Cordeiro de, Produtos transgênicos na agricultura-questões técnicas, ideológicas e políticas. Cadernos de Ciência \& Tecnologia. Brasília, V.18, n.1, p.117-145, jan./abr. 2001

ARBUCKLE T, Lin Z and Mery L An exploratory analysis of the effect of pesticide exposure on the risk of spontaneous abortion in an Ontario farm population. Envir. Health Perspectives 2001, 109, 851-60.

Canadian Food Inspection Agency Canada Plant Health and Production Division, Plant Biosafety Office 2001, Decision Document DD95-02: Determination of Environmental Safety of Monsanto Canada Inc.'s Roundup ${ }^{\circledR}$ Herbicide-Tolerant Brassica napus Canola Line GT73.

CASAFE. Cámara de Sanidad Agropecuaria y Fertilizantes. 2004. Estatísticas. Disponível em: http://www.casafe.org.ar/ mediciondemercado.html Acesso em 02 de Setembro 2009.
CASSMAN, K.G. Ecological Intensification

of cereal production systems: yield potencial, soil quality and precision agriculture. Proceedings of the National Academy of Sciences, Washington, DC, v. 96, p. 59525959, 1999.

Cerdeira, Antonio L.; Duke, Stephen O. The Current Status and Environmental Impacts of Glyphosate-Resistant Crops: A Review Journal of Environmental Quality v. 35 no. 5 (September/October 2006) p. 1633-58, 2006

CHAMPION, G.T. et al. Crop management and agronomic context of the Farm Scale Evaluations of genetically modified herbicidetolerant crops. Philosophical Transactions of the Royal Society of London, B, London, v. 358, p. 1801-1818, 2003.

CLEMENTS C, Rapph S and Petras M. Genotoxicity of select herbicides in Rana catesbeiana tadpoles using the alkaline singlecell gel DNA electrophoresis (comet) assay. Env. Mol. Mutagenesis 29, 277-88.

COSTANZA, R.; D’ARGE, R.; GROOT, R.; FARBER, S.; GRASSO, M.; HANNON, B.; LIMBURG, K.; NAEEM, S.; O’NEIL, R. V.; PARUELO, J.; RASKIN, R. G.; SUTTON, P.; BELT, M. VAN DEN. The value of the word's ecosystem services and natural capital. Nature, London, v. 387, n. 6630, p. 253-260, 1997.

CUMMINS J. Glyphosate and glyphosatetolerant crops. Impacts on health and the environment. ISIS Report, June 2002; also submitted to the World Health Organization and posted on ISIS members' website, www.isis.org.uk; updated April 2003.

DALlEGRAVE E, DiGiorgio F, Coelho R, Pereira J, Dalsenter P and Langeloh A. The teratogenic potential of the herbicide glyphosate-Roundup in Wistar rats. ToxicologyLetters 2003, 142, 45-52.

DORES, Eliana Freire Gaspar de Carvalho Contaminação do ambiente aquático por pesticidas. Estudo de caso: águas usadas para

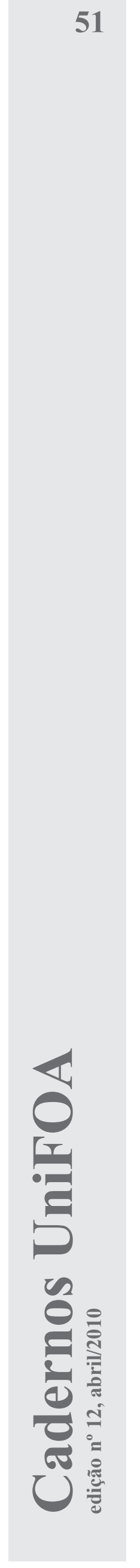


consumo humano em Primavera do Leste, Mato Grosso - análise preliminar Quím. Nova vol.24 no.1 São Paulo Jan./Feb. 2001

Em defesa de um Mundo sustentável sem transgênicos. Grupo de Ciência Independente. São Paulo, Editora Expressão Popular 2004. Disponível em: http://www.expressaopopular. com.br/pdfs/por\%20um\%20mundo.pdf Acesso em 22 de Setembro de 2009.

FERNANDES, Gabriel Biaconi. Chega de manipulação. VEIGA, José Eli (Org.) Transgênicos: sementes da discórdia. São Paulo: Editora SENAC, 2007.

FREIXO, Amanda Batista et al.. Produtos Transgênicos - aceitá-los ou não? Disponível em: http://www.unifae.br/publicacoes/pdf/ art_cie/art_31.pdf Acesso em 02 de Outubro de 2009.

GARRY V, Harkins M, Erickson L, Long S, Holland S and Burroughs B. Birth defects, seasons of conception and sex of children born to pesticide applicators living in the red river valley of Minnesota, USA. Envir. Health Perspectives (Suppl. 3) 2002, 110, 441-9.

GIANESSI, L. P.; SILVERS, C. S.; SANKULA, S.; CARPENTER, J. E. Plant biotechnology: current and potential impact for improving pest management in U.S. agriculture: an analysis of 40 case studies. Washington, DC: National Center for Food and Agricultural Policy, 2002.

GOLDBURG, R.J. Environmental concerns with the development of herbicide tolerant plants. Weed Technology, Champaign, v.6, n.3, p.647-652, 1992.

GRISOLIA C. A comparison between mouse and fish micronucleus test using cyclophosphamide, mitomycin $\mathrm{C}$ and various pesticides. Mut. Res. 2002, 400, 474, 1-6.

GUERRANTE, R. D. S. Transgênicos: uma visão estratégia. Rio de Janeiro: Interciência, 2003.

HARRISON, D. Developing herbicide tolerant crop cultivars: introduction. Weed
Technology, Champaign, v.6, n.3, p.613- 614, 1992.

Interferências no agrossistema e riscos ambientais de culturas transgênicas tolerantes a herbicidas...Cadernos de Ciência \& Tecnologia, Brasília, v. 21, n. 1, p. 11-81, jan./ abr. 2004

JAIME E. García G. Cultivos genéticamente modificados: las promesas y las buenas intenciones no bastan Rev. Biol. Trop. (Int. J. Trop. Biol. ISSN-0034-7744) Vol. 55 (2): 347-364, June 2007

KOVACS, Michelle Helena. A Maçã Proibida: os Alimentos Geneticamente Modificados e a Moral Religiosa, a Proposição da Tipologia de Risco Percebido do "Paradoxo de Adão" RAC-Eletrônica, v. 2, n. 1, art. 4, p. 54-67, Jan./Abril 2008

LIOI M, Scarfi M, Santoro A, Barbeiri R, Zeni O, Barardino D and Ursini M. Genotoxicity and oxidative stress induced by pesticide exposure in bovine lymphocyte cultures in vitro. Mut. Res. 1998, 403, 13-20.

MANN R and Bidwell J. The toxicity of glyphosate and several glyphosate formulations to four species of southwestern Australian frogs. Archives of Environ. Contam. Toxicol. 1999, 36, 193-99.

MARK EJ, LORRILON O, BOULBEN S, HUREAU D, DURRAND $G$ and Belle R. Pesticide roundup provokes cell cycle dysfunction at the level of CDK1/Cyclin B activation. Chem. Res. Toxicol. 2002, 15, 326-31.

MONQUERO, P. A. Plantas transgênicas resistentes aos herbicidas: situação e perspectivas. Bragantia, Campinas, v.64, n.4, p.517-531, 2005

MOREIRA, R. J. Críticas ambientalistas à revolução verde. Estudos Sociedade e Agricultura, no 15, outubro, 2000, p.39-52.

MOROWATI M. Histochemiccal and histopathological study of the intestine of the earthworm exposed to a field dose of the 
herbicide glyphosate. The Environmentalist 2000, 20, 105-11.

NAFZIGER, E. D. Soybean production in the Midwestern USA: technologies for sustentainable and stable yields. In: MOSCARDI, F; HOFFMANN-CAMPO, C. B.; SARAIVA, O. F.; GALERANI, P. R.; KRZYZANOWSKI, F. C.; CARRÃOPANIZZI, M.C.(Ed.). World soybean research conference. Londrina: Embrapa Soja, 2004. p. 523-530. (Embrapa Soja. Documentos, 228).

NODARI, R. O.; GUERRA, M. P. Plantas Transgênicas: Avaliação e biossegurança, 1999. Disponível em: http://66.102.1.104/scholar?hl=pt$\mathrm{BR} \& 1 \mathrm{r}=\& \mathrm{q}=\mathrm{cache}: 5 \mathrm{~T} \_6 \mathrm{UJD} 0 \mathrm{c} 4 \mathrm{gJ}: \mathrm{acd}$. ufrj.br/consumo/leituras/lg_nodari_1999. $\mathrm{rtf}+$ conflitos $\% 3 \mathrm{~B}+$ transgenicos. Acesso em 16 de Setembro de 2009.

ODILON, A. M., et al. Poluição pelas águas pluviais. Disponível em: http://www2.uel.br/ pessoal/amanthea/ctu/arquivos/seminarios/1. m6.poluicao_monogr07.pdf. Acesso em 09 de Setembro de 2009.

PAPA, J.C.M.; FELIZIA, J.C.; ESTEBÁN A.J. Cambios en la flora de malezas como consecuencia del cambio tecnologico en Argentina: malezas novedosas que pueden afectar el cultivo de la soya. In: CONGRESSO BRASILEIRO DE SOJA E MERCOSOJA, 2., Foz de Iguaçu, 2002. Anais. Foz de Iguaçu, EMBRAPA, 2002. p. 346-354.

PELUSO, M.; MUNNIA A.; BOLOGNISI C.; and PARODI S. P32-Postlabeling detection of DNA adducts in mice treated with the herbicide roundup. Environmental and Mol. Mutagenesis 1998, 31, 55-9.

GONÇALVES, C. W. P. Geografia da riqueza, fome e meio ambiente: pequena contribuição critica ao atual modelo agrário/agrícola de uso de recursos naturais. OLIVEIRA, Ariovaldo Umbelino e MARQUES, Marta Medeiros (ORGs.) O campo no século XXI. São Paulo: editora Casa amarela, pp. 207-254, 2004.

QUILES, L. M. Alimentos transgênicos. Disponível em: http://www.nutrociencia.
com.br/upload_files/arquivos/Alimentos_ Transgenicos.doc Acesso em 05 de Setembro de 2009.

RIBEIRO, M. L. R. Contaminação de águas subterrâneas por pesticidas: avaliação preliminar Quím. Nova vol.30 no.3 São Paulo May/June 2007 -

RIFKIN, J.O Século da Biotecnologia. São Paulo, Mkron Books, 1999.

ROSA, R. A. A questão dos alimentos transgênicos e o direito ambiental. Disponível em: http://www.carbonell-law. org/NuevoDiseno/ozonomio/revista21/ Articulos/articulo_brasil.doc . Acesso em 19 de Setembro de 2009

ROSSET, P. A nova revolução verde é um sonho. Rede de Direitos Humanos e Cultura, 2002. Disponível em: http://www.dhnet.org. br/w3/fsmrn/biblioteca/68_peter_rosset.html. Acesso em 19 de Setembro de 2009

ROY, D. B. et al. Invertebrates and vegetation of field margins adjacent to crops subject to contrasting herbicide regimes in the Farm Scale Evaluations of genetically modified herbicidetolerant crops. Philosophical Transactions of the Royal Society of London, v. 358, p. 18791898, 2003.

SAGPyA -SAGPyA Secretaría de Agricultura, Granadería, Pesca y Alimentos. FOB oficiales. October 2004. Disponível em: http://www. sagpya.gov.ar/new/0-0/agricultura/ diario/ fobanto/fob.htm. Acesso em 05 de Setembro de 2009

SCHONBRUNN E, Eschenburg S, Shuttleworth WA, Schloss JV, Amrhein N, Evans JNS and Kabsch W. Interaction of the herbicide glyphosate with its target enzyme 5enolpyruvylshikimate 3-phosphate synthase in atomic detail. PNAS 2001, 98, 1376- 80.

SIQUEIRA, J. O. et al., Interferências no agrossistema e riscos ambientais de culturas transgênicas tolerantes a herbicidas e protegidas contra insetos. Cadernos de Ciência 
SZAREK J, Siwicki A, Andrzewska A, TerechMajeska E and Banaszkiewicz T. Effect of the herbicide roundup on the ultrastructural pattern of hepatocytes in carp. Marine Envir. Res. 2000, 50, 263-66.

TILMAN, D.; FARGIONE, J.; WOLFF, B.; D'ANTONIO, C.; DOBSON, A.; HOWARTH, R.; SCHINDLER, D.; SCHLESINGER, W.H.; SIMBERLOFF, D.; SWACKHAMER, D. Forecasting Agriculturally driven global environmental change. Science, Washington, DC, v. 292, p. 281-284, 2001.

VALOIS, A. C. C. Importância dos transgênicos para a agricultura. Cadernos de Ciência \& Tecnologia, Brasília, v. 18, p. 27$53,2001$.

VIDAL, R.A. Herbicidas: Mecanismo de ação e Resistência de plantas. Porto Alegre: Universidade Federal do Rio Grande do Sul, 1997. $165 \mathrm{p}$

VIEIRA, L. G. E. Organismos Geneticamente Modificados: Uma tecnologia controversa. Revista Ciência Hoje. V.34, n.203. Abril, 2004.

WALSH L, McCormick C, Martin C and Stocco D. Roundup inhibits steroidogenesis by disrupting steroidogenic acute regulatory protein expression. Envir. Health Perspectives 2000, 108, 769-76.

"Weed Killer", The Progressive, July 1987, Disponível em: http://www. naturescountrystore.com/roundup/page3. html. Acesso em 13 de Setembro de 2009.

WIESE, D.L. Future impact of crops with modified herbicide resistance. Weed Technology, Champaign, v.6, n.3, p.665-668, 1992.

\section{Endereço para Correspondência:}

Taís de Souza Santos

Médica Veterinária

taisss21@yahoo.com.br

Rua 7 n $^{\circ}$ 273,

Bairro Jardim Veneza, Volta Redonda.

CEP 27285-480 